\title{
Income and Beyond: Taking the Measure of Child Deprivation in the United States
}

\author{
Raffaele Ciula $\cdot$ Curtis Skinner
}

Accepted: 8 April 2014

(C) Springer Science+Business Media Dordrecht 2014

\begin{abstract}
Comparatively little work has been done in the United States to develop multidimensional measures of child deprivation using individual level data. Our research, using Panel Study of Income Dynamics/Child Development Supplement data for a sample of older children and adolescents, introduces an experimental measure to demonstrate the new insights in child well-being that can be gained by looking beyond family income. Besides low income, our measure includes 16 indicators of deprivation encompassing child, parental, familial, and environmental conditions associated with poor outcomes in childhood and adulthood. We describe the surprisingly high incidence of deprivation among the sample children and examine differences by demographic characteristics. We calculate correlations among low income and other indicators of deprivation to understand how children are likely to be exposed to multiple deprivations. Using multivariate modeling, we examine the joint association of income and non-income contextual indicators with three child outcome deprivations: poor health, low social/emotional well-being, and poor basic learning skills. We find that the multidimensional measure provides valuable information about children at risk for poor development outcomes not captured by more standard income poverty and material hardship measures. The paper concludes with suggestions for public policy initiatives that may help reduce child exposure to these risk factors and ameliorate their effects.
\end{abstract}

Keywords Child well being $\cdot$ Child deprivation · Multidimensional measure of deprivation $\cdot$ Poverty $\cdot$ Income

R. Ciula

Italian Revenue Agency, Rome, Italy

e-mail: raffaele.ciula@agenziaentrate.it

C. Skinner $(\triangle)$

National Center for Children in Poverty, Columbia University, New York, NY 10027, USA

e-mail: skinner@nccp.org 


\section{Introduction}

What does it mean to be a disadvantaged child in the United States in the 21st century? Traditionally, poverty and disadvantage have been measured in income terms: if a family falls below a certain income threshold, the family is deemed poor. Having a family income adequate to meet basic material needs is certainly essential to any conception of child well-being. Yet mounting evidence suggests using income alone as a measure of deprivation gives but a partial accounting of children at risk for poor health and development outcomes in childhood and low socioeconomic status in adulthood.

In recent years, innovative research, much of it conducted in Europe and Latin America, has devised broader measures of disadvantage that use individuals, families, or households as the unit of observation, and include such socioeconomic and environmental variables as child and parental access to health care, neighborhood crime and pollution, and the quality of parent-child relationships. There is evidence that these measures may usefully complement income-based poverty measures in identifying children at risk and appropriate public policies to foster positive outcomes.

Comparatively little work has been done in the United States to develop such multidimensional measures of child deprivation using family-level data. This paper introduces an experimental measure to illustrate the new insights in child well-being that can be gained by looking beyond family income. Besides income, our measure includes 16 indicators of deprivation encompassing child, parental, familial, and environmental conditions associated with poor outcomes in childhood and adulthood. We describe the surprisingly high incidence of deprivation among older children and adolescents aged 10 to 19 years in the United States, and examine differences in this incidence by demographic characteristics. We examine correlations among low income and other indicators of deprivation to understand how children are likely to be exposed to multiple deprivations. Finally, we use multivariate modeling to explore the joint association of income and non-income contextual deprivation indicators with three outcome deprivation indicators for children: poor health, low social/emotional wellbeing, and poor basic learning skills. We conclude with suggestions for public policy initiatives that may help reduce child exposure to these risk factors and ameliorate their effects.

\section{Emerging Research on Multidimensional Deprivation and Child Outcomes}

The concepts of "poverty," "deprivation," and "well-being" are historical, social constructs, with no fixed definition across time and space. Social expectations and norms inform these concepts. In a broad sense, the three terms can be understood as communicating a common notion of what a given society defines as acceptable conditions of life. In this paper, we generally use the term "poverty" in the traditional sense of measuring low family income. We use the terms "deprivation" (negatively) and "well-being" (positively) when referring to child outcomes measured by multiple quality-of-life indicators, including income and non-income variables.

Family material security — defined here as having sufficient income, assets, and other resources, including social safety net supports, to provide an adequate level of 
consumption - is strongly associated with healthy child development and better socioeconomic outcomes for adults. ${ }^{1}$ But research shows that growing up in a materially poor family is but one of a number of important risk factors associated with inferior child and adult outcomes (Haveman and Wolfe 1995; Aber, Morris and Raver 2012). The evidence suggests that parental health and education (Haveman and Wolfe 1995; Peters and Mullis 1997; Axinn, Duncan and Thornton 1997; Guryan, Hurst and Kearney 2008; Pedersen and Revenson 2005), the quality of the child-parent relationship (Waldfogel 2006; Gerard and Buehler 2004; Desha, Nicholson and Ziviani 2011), and social and environmental conditions in the home (McLoyd et al. 1994; Tubbs and Aber 2013; Crouter, Head and McHale 2004; Leventhal and Newman 2010), the neighborhood (Spencer et al. 1997; Gerard and Buehler 2004; Leventhal and BrooksGunn 2000; Sharkey et al. 2012) and at school (Valois et al. 2001; Moore, Huebner and Hills 2012; Nansel et al. 2001) may independently influence child development and the experience of poverty over the life course. These findings are consistent with a socioecological model of human development that emphasizes the mutually conditioning influences of the child's individual characteristics with those of family, peers, school, neighborhood, and other social institutions (Bronfenbrenner 1979).

Significantly, the new research shows that living in an income-poor family does not fully predict whether a child experiences deprivation under broader measures of wellbeing, although often there is considerable overlap. Some low-income households experience few additional deprivations and some higher-income households experience many (Whelan et al. 2001). For example, the Poverty and Social Exclusion Survey of Britain found little overlap among people classified as poor under three different definitions: (1) having relatively low income, (2) being subjectively poor (that is, lacking the minimum income judged adequate to live "decently," according to surveys), and (3) lacking socially perceived necessities based on a representative survey (including material goods and time/resources to meet family and social obligations) (Gordon et al. 2000; Bradshaw and Finch 2003).

At the same time, many specific deprivations commonly used in multidimensional measures of well-being are more prevalent among low income families and may act to help perpetuate poverty across generations by adversely affecting a child's physical and mental health and cognitive development, with repercussions on school performance (Aber, Morris and Raver 2012; Haveman and Wolfe 1995). ${ }^{2}$ Notably, parental stress associated with income poverty is, in turn, associated with less responsive and consistent parenting, harsher parental punishment, and negative impacts on child anxiety, depression, and cognitive development (Gershoff et al. 2007). Poor families are also more likely to live in sub-standard housing and in neighborhoods that are noisy, polluted, crime-ridden, and lacking in basic cultural and recreational amenities, such as libraries and safe and clean playgrounds and parks (Leventhal and Newman 2010; Brooks-Gunn, Duncan and Aber 1997a). Low-income parents are more likely to be less

\footnotetext{
${ }^{1}$ The research literature is vast. For brief summaries, see Magnuson and Votruba-Drzal (2009) and BrooksGunn and Duncan (1997).

${ }^{2}$ The statistical evidence shows that children in the United States who grow up in poor families are more likely to experience poverty as adults compared to children who grow up in non-poor families (see, for example, Jantii 2009). The causal mechanisms linking poverty outcomes across the individual life course and across generations are the subject of vigorous research and debate (see, for example, Nelson, Martin and Featherstone 2013 and Magnuson and Votruba-Drzal 2009).
} 
educated, unemployed or underemployed, and in worse health than parents with higher incomes (Jiang, Ekono and Skinner 2014; Evans, Wolfe and Adler 2012). These deprivations - often mediated through a physiological stress response in parent and child - are hypothesized to have deleterious effects on child health, well-being, cognitive development, and educational achievement (Brooks-Gunn et al. 1997b; Menaghan, Kowaleski-Jones and Mott, 1997; Farah et al. 2007; Gruenewald et al. 2012; Chen, Schreier and Chan 2012; Cohen et al. 2010).

\section{Multidimensional Well-being and International Policymaking}

Responding to the emerging evidence, a number of governments and multilateral organizations have adopted multidimensional deprivation measures to better understand their disadvantaged populations and develop more effective anti-poverty policies. Beginning in 1990, the United Nations Development Programme (UNDP) has published an annual Human Development Report that ranks nations according to a Human Development Index. This widely referenced measure includes health and educational attainment indicators along with national per-capita income. In 2010, the UNDP inaugurated an experimental Multidimensional Poverty Index designed to compare the incidence of acute poverty in developing nations. This household-based index is comprised of ten weighted indicators assessing basic health, education, and household living conditions. The household is classified as poor if its deprivation score (the sum of each deprivation multiplied by its weight) exceeds a cut-off value of $33.3 \%$, or one-third of the weighted indicators (Malik 2013).

In 2009, Mexico adopted a multidimensional method as its official poverty measure. The Oxford Poverty and Human Development Initiative, a leader in multidimensional poverty research, advised the Mexican government on developing the new householdlevel measure, which includes indicators for income, education, health services, social security, housing conditions, nutrition, and social cohesion (comprising a measure of income inequality, among other variables). The Oxford group's methodology for multidimensional poverty measurement is detailed in Alkire and Foster (2011). A person whose income is below what is needed to meet basic needs and who has at least one "social deprivation" among the five listed above (excluding social cohesion) is considered poor according to the Mexican multidimensional standard. A person whose income is below that needed to meet basic nutritional needs and who has three or more social deprivations is considered extremely poor. In 2012, 45.5\% of Mexico's population was poor according to the multidimensional standard and $9.8 \%$ was extremely poor (Consejo Nacional de Evaluación de la Política de Desarrollo Social 2009, 2012). Produced biannually, the new poverty measure allows policymakers to better understand the links between income poverty and specific social deprivations for specific populations at the national and state levels and to track progress in reducing these deprivations over time.

Declaring poverty reduction a national priority, the Colombian government recently adopted a household-based, multidimensional poverty index with concrete targets to reduce the share of people experiencing specific deprivations in the domains of education, health, child nutrition, child labor, adult employment, and access to public utilities and housing conditions (Oxford Poverty and Human Development Initiative 
2013a). The government has set an overall target of reducing multidimensional poverty from $35 \%$ of the population in 2008 to $22 \%$ in 2014 . The Oxford group reports that Bhutan, El Salvador, Malaysia, and regions in Brazil and China have produced or are in the process of developing multidimensional poverty measures (Oxford Poverty and Human Development Initiative 2013b).

Broader measures of social well-being and deprivation are also taking root in Europe. The European Union (EU) addresses poverty and social exclusion as a joint problem requiring a broad range of policy initiatives with the goal of enabling every citizen to fully participate in ordinary life, both materially and socially. In 2001, the EU adopted a set of 18 statistical indicators (the "Laeken Indicators") to measure poverty and social exclusion, including indicators of income inequality, persistent poverty, labor force attachment, health status, and educational attainment (Atkinson, Marlier and Nolan 2004). The EU has targeted bringing 20 million people out of poverty and social exclusion by the year 2020 with policy actions that address gender and racial inequities, the labor market, minimum income support, healthcare, education, housing, and access to basic banking accounts (European Commission 2013).

\section{Assessing Multidimensional Child Well-being in the United States}

Interest in the multidimensional approach to understanding poverty and deprivation is growing among academics and advocates in the United States, although research still lags well behind efforts elsewhere in the world and has not yet engaged policymakers. ${ }^{3}$ A notable recent innovation is the Social Science Research Council's Measure of America project, which adapts the U.N.'s Human Development Index to produce an annual American Development Index. It is comprised of indicators for life expectancy at birth, school enrollment, educational degree attainment, and median earnings, with data available at the national, state, and local levels. ${ }^{4}$

Researchers are also beginning to apply multidimensional measures to the study of U.S. child well-being (Ben-Arieh 2008). In 2001, the Columbia University Institute for Children and Family Policy convened a notable conference examining U.S. child deprivation under the social exclusion paradigm. ${ }^{5}$ Useful advances have been made in recent years in measuring deprivation at the neighborhood level and exploring the relationship between these geographically-based indicators and child outcomes. Using principal components analysis, Lynne C. Messer and colleagues developed a census tract-level deprivation index that includes income/poverty, education, employment, housing, and occupation, and observed an association between neighborhood deprivation and adverse birth outcomes in their study areas (Messer et al. 2006). Similarly, Gopal K. Singh and Michael D. Kogan constructed a U.S. deprivation index at the

\footnotetext{
${ }^{3}$ Of 111 citations returned from searching the term "multidimensional deprivation" in the journal Social Indicators Research only five referred to applied research in the United States and none referred to child deprivation specifically. Recent poverty measurement research in the United States - both academic and governmental - has generally focused on another goal: improving the measurement of income poverty. For a summary of recent innovations in income-poverty measurement, see Engelhardt and Skinner (2013).

${ }^{4}$ See https://www.measureofamerica.org/

${ }^{5}$ Conference papers were collected in a published volume (Kahn and Kamerman 2002). See particularly the chapter by Aber, Gershoff, and Brooks-Gunn (2002).
} 
county, census tract, and zip code levels comprised of selected indicators of education, occupation, wealth, income distribution, unemployment rate, poverty rate, and housing quality (Singh and Kogan 2007). They found that the mortality gap between children living in the most deprived neighborhoods compared to those living in the least deprived neighborhoods increased substantially between the years 1969 and 2000, even as the overall child mortality rate declined sharply.

Several leading research and advocacy organizations track child well-being across multiple dimensions at the national and state levels of aggregation. The Foundation for Child Development publishes a National Child and Youth Well-Being Index developed by Kenneth Land and colleagues (Land, Lamb and Mustillo 2001). Comprised of twenty-eight indicator variables covering the domains of family economic well-being, safe/risky behavior, social relationships, emotional/spiritual well-being, community engagement, educational attainment and health, ${ }^{6}$ the annual index begins in 1975, permitting analysis of trends over many years. The Child Trends Databank includes more than 100 indicators of risk and positive development for children. ${ }^{7}$ The KIDS COUNT Data Center similarly follows hundreds of child well-being indicators in the domains of economic well-being, education, health, and family and community, among others, and ranks the performance of states. ${ }^{8}$ The Children's Defense Fund provides state-level data and rankings in early childhood development, education, health, nutrition, and poverty that are drawn from numerous underlying indicators; for example, the health dimension includes the percentage of uninsured children, the percentage of children enrolled in the state Child Health Insurance Program, and immunization rates, among other indicators. ${ }^{9}$ Finally, the National Center for Children in Poverty publishes annual fact sheets and an online data tool that assesses risk factors at the state and national levels associated with poor health, school and development outcomes for young children. Risk factors include low parental education, parental unemployment, single parent household, household without English speakers, residential instability, and lack of health insurance coverage. ${ }^{10}$

The federal government is also engaged in tracking child well-being across a wide spectrum of indicators. The Federal Interagency Forum on Child and Family Statistics publishes an important annual compendium of 41 indicators across the seven domains of family and social environment, economic circumstances, health care, physical environment and safety, behavior, education, and health status, including valuable trend data (Federal Interagency Forum on Child and Family Statistics 2013). The report, America's Children: Key National Indicators of Well-being, also highlights critical data gaps within each domain to guide continuous improvement of this resource.

These resources are very useful for following trends in child well-being at an aggregate level. However, they are not designed to analyze deprivation at the level of the individual child, and hence cannot answer such critical questions as how specific deprivations are correlated at the individual level, how many children experience

\footnotetext{
${ }^{6}$ See http://fcd-us.org/our-work/child-well-being-index-cwi/national-cwi

${ }^{7}$ See http://www.childtrends.org/databank/

${ }^{8}$ See www.datacenter.kidscount.org

${ }^{9}$ See http://www.childrensdefense.org/child-research-data-publications/data/state-data-repository/children-inthe-states.html

${ }^{10}$ See Young Child Risk Calculator web-based tool at http://www.nccp.org/tools/risk/ and Basic Facts about Low-Income Children at http://www.nccp.org/publications/pdf/text_1089.pdf
} 
multiple deprivations, and how the incidence of multiple deprivations differs by gender and race/ethnicity. Kristin A. Moore and her colleagues at Child Trends and the Annie E. Casey Foundation broke new ground in 2007 by constructing such a child-based well-being index, drawing on data from the National Survey of Children's Health (Moore et al. 2008). Well-grounded in theory and empirical evidence, this methodologically sophisticated measure comprises 69 indicators in four individual well-being domains and three contextual domains for children in two age groups: 6 to 11 years old and 12 to 17 years old. The individual well-being domains include indicators for physical health, psychological health, social health, and educational/intellectual attainment that directly measure child well-being. The contextual domains include indicators at the family, household, and neighborhood levels - such as parental engagement with the child, household income, and neighborhood safety - that influence, but do not directly measure, child well-being.

This index produced a number of striking findings of interest and value to researchers in child poverty and development. Less than one-third of younger American children and less than one quarter of older children experienced well-being in all four domains of individual well-being. In each age group and each domain, girls scored higher than boys in well-being, and white children scored higher than black and Hispanic children. While only $5.4 \%$ of white children aged 6 to 11 years old were deprived in all four domains, $16 \%$ of black children and $13 \%$ of Hispanic children were so deprived. Children with household incomes below $200 \%$ of the federal poverty level also fared worse in each domain and age group. Only $4.4 \%$ of all higher-income children were deprived in all four domains compared to $14.3 \%$ of lower-income children. Similar disparities were observed for the sample of older children, and the racial/ethnic and income group gaps are even larger with respect to the contextual domains.

The study conducted by Moore and colleagues marks a significant advance in measuring multi-dimensional child well-being in the United States. Inevitably, it is also subject to certain limitations, as the authors note. The National Survey of Children's Health data source is intended to provide a detailed assessment of child health, and information on some other important indicators of child well-being is comparatively sparse or missing. In particular, the $\mathrm{NSCH}$ has comparatively little information on socioeconomic and environmental conditions at the family and neighborhood levels that are known to influence child outcomes, as noted above. The survey respondent is the adult in the household with the best information about the child's health, and no information is gathered directly from the child or from other assessments. $^{11}$

\section{A New Look at American Child Deprivation}

Surprisingly, the innovative research described above has stimulated no new work assessing individual child well-being in the United States from a multidimensional perspective, according to our review of the published literature. This report presents

\footnotetext{
${ }^{11}$ The survey randomly selects one child in each household as the subject for the adult interview. See BenArieh (2005) for a discussion of the importance of including children's subjective assessments of well being.
} 
preliminary findings from a new study of child well-being using such individual-level data. Our specific interest lies in examining the incidence of specific deprivations associated with negative child development outcomes and how a child's experience of these deprivations varies by gender, race/ethnicity, and family income. We are also interested in how specific deprivations are associated with one another. While we use only 17 indicators, compared to the 69 Moore and colleagues use, our indicators are consistent with the latter's four individual domains (comprised of physical, psychological and social health, and educational/intellectual attainment indicators) and three contextual domains (comprised of family, household, and neighborhood indicators). ${ }^{12}$ Despite this parsimony, our model includes important indicators associated with child development outcomes in the research literature that do not appear in the Moore and colleagues study, such as the child's exposure to violence, family financial stress, parental unemployment, housing conditions, neighborhood noise and trash, and cultural isolation. In addition, our data include the child's own assessment of critical aspects of well-being - notably, the experience of being bullied and threatened, social and emotional well-being, and basic learning skills - along with responses collected from the primary caregiver and the survey interviewer.

\subsection{Data and Methodology}

This study draws on data from the 2007 Panel Study of Income Dynamics (PSID), including the Child Development Supplement (CDS). The data are collected from interviews with both primary caregivers and children. In addition, some data are provided by interviewer observation. Children and adolescents in the sample range in age from 10 to 19 years old, and the sample consists of 5,353 observations of children and parents. Weights are used to make the sample nationally representative of children and their primary caregivers. Descriptive statistics for the sample are shown in Table 1.

Although designed for longitudinal research, the PSID/CDS is chosen as the data source for this point-in-time deprivation study because it provides a very rich source of variables-drawn from both caregivers and directly from children - with which to measure deprivation across many domains. ${ }^{13}$ The quality of PSID/CDS data collection is also high (Sastry and Duffy, 2012). We intend to use the PSID longitudinally in future projects examining the associations between childhood deprivations and adult outcomes.

\footnotetext{
${ }^{12}$ In general, there is broad agreement in the social indicator literature on the domains that are important to include when measuring multidimensional child well-being. Cf., Fernandes, Mendes and Texeira (2001a, b).

${ }^{13}$ As the CDS User Guide states, "The CDS gathers a broad array of measures on development outcomes across the domains of health, psychological well-being, social relationships, cognitive development, achievement motivation, and education as well as a number of measures of the family, neighborhood, and school environments in which the sample members live and learn. The breadth and depth of measurement offer a substantially rich resource to study the development of children and teens alike from infancy/early childhood through middle childhood and adolescence." (University of Michigan and Institute for Social Research 2012
} 
Table 1 Child Descriptive Statistics, PSID Sample

\begin{tabular}{ll}
\hline Mean age & 13.5 \\
\hline Percentage female & 51.5 \\
Percentage male & 48.5 \\
Percentage white & 74.5 \\
Percentage black & 14.1 \\
Percentage Hispanic (can be of any race) & 18.3 \\
Unweighted total sample size & 5,353 \\
Unweighted child sample size & 1,623 \\
\hline
\end{tabular}

\subsection{Child Deprivation Variables}

As briefly reviewed above, social science and public health research has identified important risk factors to healthy child development and well-being across multiple domains. Among them are material poverty, access to health care, relations with parents and peers, parent's educational attainment and employment history, exposure to crime, and physical conditions in the child's house and neighborhood. This study draws on this work to define 17 variables in these and other domains, subject to the limitations of the PSID data set (Table 2). All variables are categorical, coded as 1 if the child experiences the deprivation and 0 if the child does not. Some of the deprivations are defined from a single interview question (e.g., child is in poor health), and some are defined from multiple interview questions (e.g., child is bullied). More detailed explanations of the construction of these composite variables are given in endnotes.

Our initial, descriptive analysis examines the associations and incidence of all 17 deprivations among children. We then conduct multivariate analysis to examine the relationships between three deprivations treated as outcomes-poor child health, low social/emotional well-being, and poor basic learning skillsand the remaining deprivations. We follow Moore et al. (2008) in our selection of these outcome indicators, which are broadly consistent with the latter's four individual domains of child well-being (physical health, psychological health, social health, and educational achievement and cognitive development), although negatively defined as deprivations in our study. By examining associations between indicators conceived as directly measuring child well-being or deprivation (such as the child's health status) and those conceived as influencing well-being or deprivation (such as whether the child has health insurance), we hope to gain deeper insight about the relationships between the family, neighborhood and social contexts of the child's life and critical developmental outcomes. $^{14}$

\footnotetext{
${ }^{14}$ Researchers have taken different approaches with respect to whether their indexes discriminate between outcome and contextual indicators. Moore et al. (2008) separate outcome from contextual indicators, while Fernandes et al. (2012b)) include both kinds of indicators in a single index. Similarly, aggregate-data indexes, such as the National Child and Youth Well-Being Index discussed above, include both outcome and contextual indicators.
} 
Table 2 Deprivation Variable Definitions

Deprivation Definition

Poor child health

Culturally isolated

Unsafe neighborhood

Uninsured

Poor housing conditions

Polluted neighborhood

Threatened

Bullied

Low parental education

Poor parental health

Parental unemployment

Low social/emotional well-being

Family financial stress

Few family activities

Poor basic learning skills

Low parental warmth

Low family income
Primary caregiver reports child's health as fair or poor

Primary caregiver reports family member seldom or never taking child to a library, theater, or museum within the past year

Primary caregiver reports child's play environment and neighborhood are unsafe

Primary caregiver reports child has no health insurance coverage

Interviewer reports observing one or more conditions: overcrowding, unclean rooms, obvious signs of recent alcohol or illegal drug consumption in the home ${ }^{\mathrm{a}}$

Interviewer reports noisy neighborhood or trash on street/sidewalk

Child reports having ever been threatened with a knife or gun

Child reports being bullied by other children about once a week or more frequently within the past month ${ }^{\mathrm{b}}$

Primary caregiver reports average educational attainment of self and spouse is 10th grade or less

Primary caregiver reports health of self and spouse averages to fair or poor on the PSID scale

Primary caregiver reports: (1) both self and spouse are unemployed, or (2) one of the two is unemployed and the family is low income

Composite index of child's response to 4 questions assessing psychological well-being and 5 questions assessing social well-being ${ }^{c}$

Primary caregiver reports not enough money is left over at the end of the month to make ends meet

Primary caregiver reports child is included in family activities less often than once a week within the past month

Child reports being less than "OK" at math and/or reading

Composite index composed of primary caregiver's response to 7 questions assessing engagement with and emotional support of the child ${ }^{\mathrm{d}}$

Family income is less than $50 \%$ of U.S. net disposable median income

a This variable is constructed from the interviewer's responses to three PSID questions (Q32K30, Q32K32, Q32K36) assessing the cleanliness of rooms in the home, whether the home has at least 100 square feet of living space per person, and whether there are obvious signs of recent alcohol or non-prescription drug consumption in the home. The variable is coded 1 if the interviewer reported one or more problematic conditions.

b This variable is constructed from the child's responses to three PSID questions (Q33H1A, Q33H1B, Q33H1C) asking how often in the past month children in school or elsewhere had: hit the child, taken the child's things, or picked on the child. The variable is coded 1 if the child reported at least one or two incidents of being hit or having things taken in the past month and/or being picked on at least two or three days per week.

c This variable is constructed from two PSID composite variables: PWB07 is the mean score for four questions asking the child how often in the past month the child felt: s/he was good at managing the responsibilities of daily life, had warm and trusting relations with other kids, had experiences that challenged him/her to grow or become a better person, and felt confident to think or express his/her own ideas and opinions. SWB07 is the mean score for five questions asking the child how often in the past month the child felt that: s/he had something important to contribute to society, s/he belonged to a community (like a social group, school, or neighborhood), society is becoming a better place, people are basically good, the way our society works makes sense to him/her. The variable is coded 1 if the mean score is $\leq 3$ for either or both EWB07 and SWB07.

d This PSID composite variable (WARMTH07 "Parental Warmth Scale") is the mean score for seven questions asking the primary caregiver how often in the past month s/he: told the child s/he loved the child, spent time doing one of the child's favorite activities, talked with the child about things the child is especially interested in, told the child s/he appreciated something the child did, talked with the child about current events, and talked with the child about the child's day. The variable is coded 1 if the mean score for the seven questions is $\leq 3$. 
Table 3 Correlations between Family Income and Non-Income Deprivations

\begin{tabular}{ll}
\hline Deprivation & Correlation coefficient \\
\hline Parental unemployment & -0.82 \\
Family financial stress & -0.75 \\
Low parental education & -0.71 \\
Poor housing conditions & -0.60 \\
Poor parental health & -0.56 \\
Polluted neighborhood & -0.51 \\
Unsafe neighborhood & -0.48 \\
Uninsured & -0.44 \\
Threatened & -0.34 \\
Few family activities & -0.34 \\
Poor child health & -0.31 \\
Low social/emotional well-being & -0.25 \\
Low parental warmth & -0.14 \\
Bullied & -0.12 \\
Poor basic learning skills & -0.07 \\
Culturally isolated & -0.06 \\
\hline
\end{tabular}

\section{Associations between Deprivations}

Correlation analysis shows considerable variation in the extent to which particular deprivations are associated with income, indicating that the measure captures some hardships that will not be proxied by a poverty measure based solely on income (Table 3). Although all correlations are negative, meaning that lower family income is associated with each deprivation, several of the deprivations - experiencing low parental warmth, being bullied, self-reported poor basic learning skills, and cultural isolation-are only weakly associated with low family income. ${ }^{15}$ In other words, many children experiencing these deprivations live in higher-income families.

Other important child variables - health status and health insurance coverage, social/ emotional well-being, family activities, and being threatened with a weapon-reveal moderate associations with family income. Conversely, important parental variablesemployment status, health, and education - are strongly correlated with family income, as are financial stress and housing and neighborhood conditions.

Many of the non-income deprivations used in the measure are correlated with one another in patterns familiar from the research literature (Table 4). Low parental education has the largest number of strong to moderate associations with other deprivation variables: parental unemployment, financial stress, poor child health, no child health insurance, and few family activities. Poor housing is correlated with a polluted neighborhood, an unsafe neighborhood, and poor child health. Perhaps unsurprisingly, low parental warmth is strongly correlated with few family activities. ${ }^{16}$

\footnotetext{
$\overline{15}$ The polychoric correlation technique is used. All correlations are significant at the one percent level.

16 The tetrachoric correlation technique is used. All correlations are significant at the one percent level.
} 
Table 4 Highly Correlated NonIncome Deprivations
Deprivations

Correlation coefficient

Poor housing conditions - Polluted neighborhood 0.66

Low parental warmth - Few family activities 0.62

Unsafe neighborhood - Polluted neighborhood 0.58

Low parental education - Parental unemployment

0.56

Family financial stress - Parental unemployment

Low parental education - Poor child health

Low parental education - Family financial stress

0.47

Poor parental health - Parental unemployment

0.46

Low parental education - Few family activities

0.45

Poor housing conditions - Poor child health

0.44

Low parental education - Uninsured

0.43

Polluted neighborhood - Parental unemployment

0.42

Poor housing conditions - Unsafe neighborhood

0.42

Polluted neighborhood - Poor parental health

0.41

\section{How are American Children Deprived?}

Strikingly, our analysis of the PSID/CDS 2007 data shows that about $84 \%$ of American children between the ages of 10 and 19 years experience at least one of the 17 deprivations used in the multidimensional deprivation measure (Table 5). ${ }^{17}$ If a disadvantaged child is defined as one experiencing three or more deprivations, $45 \%$ of American children in this age group are disadvantaged. The proportion falls to $32 \%$ if disadvantage is defined as four or more deprivations. By comparison, the proportion of children estimated to be income-poor in this study is $26 \%$.

Children living in low-income families are more likely to experience additional deprivations (besides low income) compared to children as a whole, as shown in Table 5. Fewer than three percent of these low-income children experience no additional deprivation and more than $76 \%$ experience three or more additional deprivations. Moreover, a much higher proportion of this group is severely disadvantaged, if this is defined as experiencing more than five deprivations: $44 \%$ compared to only $13 \%$ for all children. ${ }^{18}$ On average, lowincome children experience 4.8 deprivations in addition to low-income status.

Which deprivations are most common? Table 6 shows that, among all children in the 10 to 19 years age group, common deprivations span a wide range of economic, social/ emotional, educational, cultural, and neighborhood-quality variables. In addition to low income, six other deprivations each affect about one-quarter of older American children, and only two are strongly correlated with income: family financial stress and unsafe neighborhood. The multidimensional approach to child well-being captures

\footnotetext{
$\overline{17}$ This and other proportions cited are calculated by subtracting the relevant cumulative percentage from 100; for example, since $15.9 \%$ of all children experienced no deprivations, $84.1 \%$ experienced at least one deprivation.

${ }^{18}$ In the case of low-income children (defined as already experiencing one deprivation) this proportion is calculated as the percentage having four or more deprivations shown in Table 5.
} 
Table 5 Deprivation Experience, All Children and Low-Income Children

\begin{tabular}{|c|c|c|c|c|}
\hline \multirow{2}{*}{$\begin{array}{l}\text { Number of } \\
\text { deprivations }\end{array}$} & \multicolumn{2}{|l|}{ All children } & \multicolumn{2}{|c|}{ Low-income children } \\
\hline & Percentage & $\begin{array}{l}\text { Cumulative } \\
\text { percentage }\end{array}$ & Percentage & $\begin{array}{l}\text { Cumulative } \\
\text { percentage }\end{array}$ \\
\hline None & 15.9 & 15.9 & 2.5 & 2.5 \\
\hline One & 20.7 & 36.6 & 6.6 & 9.1 \\
\hline Two & 18.0 & 54.6 & 14.4 & 23.5 \\
\hline Three & 13.2 & 67.8 & 18.8 & 42.3 \\
\hline Four & 11.8 & 79.6 & 13.8 & 56.1 \\
\hline Five & 6.9 & 86.5 & 13.1 & 69.2 \\
\hline Six & 4.7 & 91.2 & 14.7 & 83.9 \\
\hline Seven & 4.3 & 95.5 & 7.4 & 91.3 \\
\hline Eight & 2.2 & 97.7 & 2.4 & 93.7 \\
\hline Nine & 0.6 & 98.3 & 4.3 & 98.0 \\
\hline Ten & 1.1 & 99.4 & 0.8 & 98.8 \\
\hline Eleven & 0.2 & 99.6 & 1.1 & 99.9 \\
\hline Twelve & 0.3 & 100 & 0.1 & 100 \\
\hline Thirteen & 0.0 & 100 & - & - \\
\hline
\end{tabular}

important and commonly experienced deprivations not proxied by income poverty,

Table 6 Incidence of Specific Deprivations, All Children and Low-Income Children

\begin{tabular}{llll}
\hline Deprivation & $\begin{array}{l}\text { All children } \\
\text { percentage }\end{array}$ & $\begin{array}{l}\text { Low-income } \\
\text { children percentage }\end{array}$ & $\begin{array}{l}\text { P value, difference of } \\
\text { proportions, two-tailed test }\end{array}$ \\
\hline Low social/emotional well-being & 26.2 & 35.1 & 0.00 \\
Low family income & 26.1 & - & - \\
Culturally isolated & 25.9 & 29.2 & 0.00 \\
Family financial stress & 25.9 & 55.7 & 0.00 \\
Bullied & 25.4 & 28.4 & 0.00 \\
Poor basic learning skills & 24.6 & 30.1 & 0.00 \\
Unsafe neighborhood & 23.7 & 41.6 & 0.00 \\
Few family activities & 17.4 & 29.5 & 0.00 \\
Low parental warmth & 14.0 & 18.7 & 0.00 \\
Parental unemployment & 13.9 & 47.5 & 0.00 \\
Poor parental health & 13.8 & 27.6 & 0.00 \\
Low parental education & 12.3 & 31.3 & 0.00 \\
Poor housing conditions & 8.8 & 20.6 & 0.00 \\
Threatened & 6.3 & 10.2 & 0.00 \\
Uninsured & 5.5 & 9.4 & 0.00 \\
Polluted neighborhood & 4.6 & 11.9 & 0.00 \\
Poor child health & 2.5 & 5.0 & 0.00 \\
\hline & & & \\
\hline
\end{tabular}


including self-assessments of low social/emotional well-being, poor basic learning skills, and being bullied.

Strikingly, children in low-income families are more likely to experience each of the remaining 16 deprivations (excluding low income) compared to children as a whole (Table 6). In many cases, the deprivation incidence for these children is twice as high or higher. The incidences of parental unemployment and financial stress are remarkably high at $48 \%$ and $56 \%$, respectively. Low-income children are also much more likely to suffer from a poor physical environment and live in sub-standard housing conditions and in unsafe or polluted neighborhoods. Of great concern, too, are much higher parental incidences of low education and poor health, with negative consequences in the labor market. Finally, more than one-third of children living in low-income families experience low social/emotional well-being, compared to the already-high incidence of one-quarter among all children. These findings are broadly consistent with those of Moore et al. (2008), who found that children with family incomes below $200 \%$ of the federal poverty line scored significantly lower than children from higher-income families in overall well-being and across the specific domains of physical health, psychological health, social health, and educational achievement and cognitive development. The high incidence of deprivation observed among low-income families across a spectrum of economic, health, educational, social/emotional, and neighborhoodquality variables suggests these deprivations and low family income tend to appear together and may demand holistic policy interventions at the macroeconomic, neighborhood, and two-generational family levels to improve family opportunity. ${ }^{19}$

\section{Child Deprivation by Gender and Race/Ethnicity}

Boys between 10 to 19 years old are considerably more likely than girls to experience at least one deprivation (Table 7). If disadvantage is measured as three or more deprivations, boys are also more likely to be disadvantaged than girls, at $48 \%$ compared to $42 \%$. While the sexes experience important economic, education, and health deprivations at roughly the same rate, there are large differences in the incidence of deprivations bearing on safety and social and emotional well-being, as shown in Table 8. Boys are much more likely to report being bullied and to have been threatened with a weapon. Boys are also more likely to be culturally isolated, have less engaged parents, and to report low social/emotional wellbeing. Girls are more likely to live in a neighborhood perceived by their primary caregiver as unsafe. Our findings that boys are more likely than girls to experience at least one deprivation is consistent with Moore et al.'s (2008) finding that older girls score higher on overall well-being and on each of four outcome domains of well-being compared to boys.

Comparing deprivation by race and ethnicity (Table 9) shows white children are much less likely to experience deprivation than either black or Hispanic children. Measuring disadvantage as three deprivations or more, $38 \%$ of white children are disadvantaged compared to $67 \%$ of black children and $71 \%$ of Hispanic children. If disadvantage is measured at four or more deprivations, the inter-group differences in disadvantage remain vast at $26 \%$ of white children compared to $51 \%$ of black children and $60 \%$ of

\footnotetext{
${ }^{19}$ Among the best-known public and private initiatives taking such a holistic approach are the Harlem Children's Zone in New York City and the federal Promise Neighborhoods program.
} 
Table 7 Percentage of All Children Experiencing One or More Deprivation by Sex

\begin{tabular}{lcc}
\hline & Boys & Girls \\
\hline None & 12.8 & 19.1 \\
One & 20.4 & 21.0 \\
Two & 18.3 & 17.7 \\
Three & 14.9 & 11.5 \\
Four & 11.9 & 11.7 \\
Five & 7.8 & 5.9 \\
Six & 4.2 & 5.2 \\
Seven & 4.7 & 3.7 \\
Eight & 2.4 & 2.0 \\
Nine & 0.8 & 0.5 \\
Ten & 0.8 & 1.4 \\
Eleven & 0.2 & 0.2 \\
Twelve & 0.6 & 0.0 \\
Thirteen & 0.0 & 0.0 \\
\hline
\end{tabular}

Hispanic children. Also notable are much higher shares of black and especially Hispanic children experiencing five or more deprivations compared to white children. As is true with income poverty, children of color in the United States disproportionately bear the burden of deprivation across a broad range of resources and living conditions important to healthy development. These findings are consistent with those of Moore et al. (2008), who found that black and Hispanic children12-17 years old were more likely than white

Table 8 Incidence of Specific Deprivations by Gender (\%)

\begin{tabular}{lrrl}
\hline & Boys & Girls & $\begin{array}{l}\text { P value, difference of } \\
\text { proportions (two-tailed test) }\end{array}$ \\
\hline Poor child health & 2.5 & 2.5 & 1.00 \\
Culturally isolated & 28.1 & 23.7 & 0.00 \\
Unsafe neighborhood & 22.0 & 25.5 & 0.00 \\
Uninsured & 6.4 & 4.6 & 0.00 \\
Poor housing conditions & 9.4 & 8.1 & 0.00 \\
Polluted neighborhood & 4.5 & 4.6 & 0.69 \\
Threatened & 9.2 & 3.3 & 0.00 \\
Bullied & 28.6 & 22.0 & 0.00 \\
Low parental education & 13.0 & 11.5 & 0.00 \\
Poor parental health & 13.7 & 13.8 & 0.81 \\
Parental unemployment & 14.2 & 13.6 & 0.15 \\
Low social/emotional & 28.5 & 23.8 & 0.00 \\
$\quad$ well-being & & & \\
Family financial stress & 25.7 & 26.2 & 0.34 \\
Few family activities & 17.6 & 17.2 & 0.38 \\
Poor basic learning skills & 25.1 & 24.0 & 0.03 \\
Low parental warmth & 16.1 & 11.7 & 0.00 \\
Low family income & 26.5 & 25.7 & 0.13 \\
\hline
\end{tabular}


Table 9 Percentage of Children Experiencing One or More Deprivation by Race/Ethnicity

\begin{tabular}{llcc}
\hline & White children & Black children & Hispanic children \\
\hline None & 18.5 & 4.4 & 7.7 \\
One & 24.0 & 12.0 & 11.9 \\
Two & 19.0 & 17.0 & 9.5 \\
Three & 12.7 & 15.8 & 11.4 \\
Four & 10.7 & 16.4 & 18.4 \\
Five & 5.7 & 8.3 & 15.9 \\
Six & 3.6 & 10.8 & 8.4 \\
Seven & 3.0 & 7.3 & 7.1 \\
Eight & 1.7 & 5.3 & 5.1 \\
Nine & 0.1 & 1.8 & 0.6 \\
Ten & 0.4 & 0.5 & 1.9 \\
Eleven & 0.1 & 0.2 & 0.5 \\
Twelve & 0.4 & 0.1 & 1.4 \\
Thirteen & 0.0 & 0.1 & 0.0 \\
\hline
\end{tabular}

children to fail to meet the criteria for well-being in any outcome or contextual domain and much less likely to achieve well-being in all domains.

Table 10 Incidence of Specific Deprivations by Race and Ethnicity (\%)

\begin{tabular}{|c|c|c|c|c|c|}
\hline & $\begin{array}{l}\text { White } \\
\text { children }\end{array}$ & $\begin{array}{l}\text { Black } \\
\text { children }\end{array}$ & $\begin{array}{l}\text { Hispanic } \\
\text { children }\end{array}$ & $\begin{array}{l}\text { P value, white/ } \\
\text { black difference } \\
\text { of proportions } \\
\text { (two-tailed test) }\end{array}$ & $\begin{array}{l}\text { P Value, white/ } \\
\text { Hispanic difference } \\
\text { of proportions } \\
\text { (two-tailed test) }\end{array}$ \\
\hline Poor child health & 1.5 & 2.8 & 5.9 & 0.00 & 0.00 \\
\hline Culturally isolated & 24.1 & 26.6 & 26.7 & 0.00 & 0.00 \\
\hline Unsafe neighborhood & 21.1 & 29.6 & 35.5 & 0.00 & 0.00 \\
\hline Uninsured & 3.8 & 8.7 & 12.2 & 0.00 & 0.00 \\
\hline Poor housing conditions & 7.5 & 15.1 & 13.8 & 0.00 & 0.00 \\
\hline Polluted neighborhood & 3.1 & 9.2 & 3.7 & 0.00 & 0.03 \\
\hline Threatened & 5.2 & 14.1 & 6.3 & 0.00 & 0.00 \\
\hline Bullied & 27.3 & 22.4 & 24.3 & 0.00 & 0.00 \\
\hline Low parental education & 9.9 & 10.2 & 42.9 & 0.57 & 0.00 \\
\hline Poor parental health & 10.9 & 23.2 & 13.9 & 0.00 & 0.00 \\
\hline Parental unemployment & 9.9 & 24.8 & 23.4 & 0.00 & 0.00 \\
\hline Low social/emotional well-being & 24.3 & 31.9 & 28.4 & 0.00 & 0.00 \\
\hline Family financial stress & 22.4 & 42.6 & 42.5 & 0.00 & 0.00 \\
\hline Few family activities & 12.8 & 26.6 & 34.9 & 0.00 & 0.00 \\
\hline Poor basic learning skills & 24.5 & 22.8 & 33.8 & 0.03 & 0.00 \\
\hline Low parental warmth & 11.6 & 19.0 & 19.3 & 0.00 & 0.00 \\
\hline Low family income & 19.2 & 56.4 & 39.4 & 0.00 & 0.00 \\
\hline
\end{tabular}


Compared to white children, Hispanic children are more likely to experience each of 17 specific deprivations with the exception of one - being bullied (Table 10). The differences are very large with respect to the economic variables - low family income, financial stress, and parental unemployment. They are also large with respect to the child's basic learning skills and parental educational attainment as well as housing conditions and neighborhood safety. In addition, Hispanic children are more likely to lack health insurance, to have a lesswarm relationship with their parents, and to engage in fewer family activities.

Black children, too, are more likely than white children to experience every specific deprivation with the exceptions of being bullied, having poor basic learning skills, and having low parental education. Among the three groups, black children have the highest incidence of living in poor housing conditions or in a polluted neighborhood and of being threatened with a weapon. Black children also fare the worst on the economic deprivation measures of low family income and parental unemployment. Also notable is the uniquely high incidence of poor parental health among black children. As is the case with Hispanic children, black children are less likely than their white peers to have a warm parental relationship and to engage in family activities.

\section{Associations between Contextual and Outcome Deprivations}

To get a better understanding of how deprivations other than low income may be associated with poor child health and development outcomes, we constructed multivariate regression models for three deprivations treated as dependent variables: poor child health, low social/emotional well-being, and poor basic learning skills. This part of the analysis follows Moore et al.'s (2008) practice of separating outcome domains that directly measure child well-being from contextual variables hypothesized to influence child well-being. We ran logistic regressions with the remaining 14 variables as independent (contextual) variables along with demographic controls for child age, child gender, Hispanic head of household, black head of household, and single parent family. Frequency weights were used, and robust standard errors adjust for the clustering of observations in families. The results of this exercise are shown in Table 11, which reports only regressors statistically significant at the five percent level or higher.

Each model reports significant regressors that have been associated with the outcome variables in the theoretical and the empirical research literatures and so provides additional support for these associations. The odds ratio is interpreted as a ratio of the probability that a child with the observed contextual deprivation experiences the outcome deprivation to the probability that a child without the contextual deprivation experiences the outcome deprivation. For example, Table 11 shows that a child living in poor housing conditions has almost five times greater odds of being in poor health than a child not living in poor housing conditions, all else equal. As documented in the brief literature review above, poor housing conditions, low parental education, and poor parental health (especially mental health) have all been associated with poor child health outcomes. The experience of being bullied has also been associated with negative cognitive outcomes and lower selfreported child well-being. There is some evidence that parental unemployment, mediated through parental stress, may negatively affect a child's school performance (Menaghan, Kowaleski-Jones and Mott 1997). Living in a neighborhood with poor environmental conditions has also been linked to lower child well-being. Consistent with the bivariate 


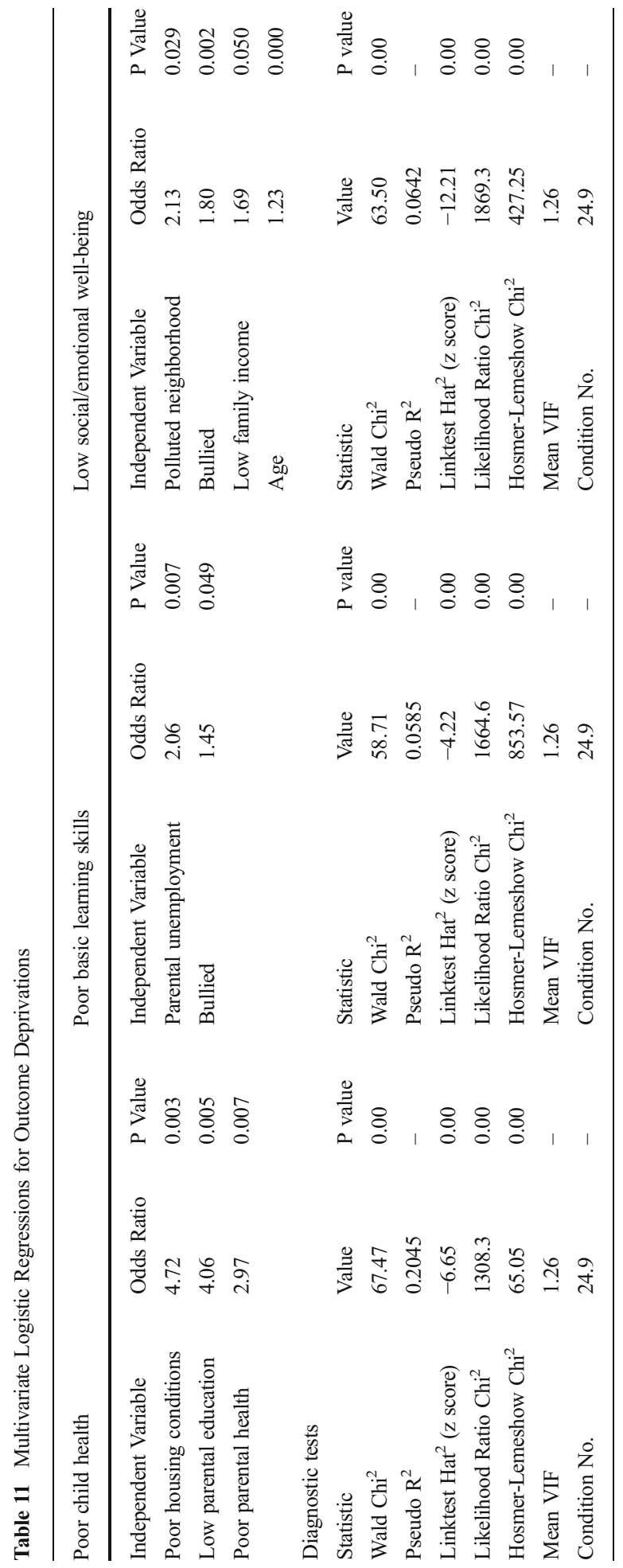


correlations reported in Tables 3 and 4, the poor child health model is the most robust of the three outcome models. Our findings of significant associations between contextual indicators and outcome indicators in models with demographic controls are consistent with Moore et al.'s (2008) regression models showing significant associations between contextual domain scores and well-being domain scores for the 12-17 year age group.

Of equal interest are the contextual variables that do not show up as statistically significant in the multivariate regressions. Low family income is found significant only in the model for social/emotional well-being, despite the higher incidence of each of the three outcome deprivations among low-income children compared to all children (reported in Table 6). The lack of statistical significance for the income regressor in the health and learning skills models does not seem to be an artifact of collinearity with the parental unemployment, family financial stress, and low parental education variables shown to be correlated with low income in Table 3. Alternative regressions (Appendix Table 12) dropping these variables do not strengthen the low income regressor or substantially change the odds ratios and significance of most of the remaining regressors in any of the three models. These findings support the argument that deprivation indicators in addition to low income are important for identifying children at risk for poor development outcomes.

Notable, too, is the models' failure to support the significance of other contextual variables for the outcomes of interest despite some evidence of such association in the literature. For example, neither living in a polluted neighborhood nor lacking health insurance is associated with poor child health in our regression exercise. Children who experience low parental warmth and engage in few family activities are not more likely to report low social/emotional well-being, according to our model. Nor are children with poorly educated parents and who make few family visits to cultural and educational institutions more likely to report poor basic learning skills. The child gender regressor is insignificant in all models despite the differences in outcome deprivation incidence between boys and girls shown in Table 8. The Hispanic and black head of household regressors are also insignificant, despite the greater variation of outcome deprivation incidence among white, black, and Hispanic children.

These models have many limitations, and they should be viewed as exploratory. Simple, cross-sectional regressions are notoriously vulnerable to variable misspecification and endogeneity. For example, Cummins (2000) has found that regression models that include subjectively-measured dependent and independent variables are prone to underestimating dependent-variable associations with objectively-measured regressors, and specifically income. Reviewing the limitations of correlational studies, Duncan and Raudenbush (2001) conclude that quasiexperimental and random assignment methods should become the standard for research studying the effects of neighborhood conditions on adolescent development and behavior. Indeed, the standard diagnostic test results shown in Table 11 suggest each model may be misspecified (indicated by significant linktest hat-square and HosmerLemeshow Chi-square values), producing biased estimators due to important omitted variables. Nevertheless, the models have some predictive power. Wald Chi-square and likelihood ratio Chi-square tests indicate each model predicts better than an interceptonly model. Low variance inflation factor values suggest that multicollinarity among regressors is not a significant problem in any model, but high condition numbers indicate the regression coefficients are unstable (these statistics are the same for each model because the regressors are the same). 
Given the open nature of the field, researchers have ample opportunity to construct alternative and improved individual-level measure of multidimensional child deprivation in the United States, using both the PSID and other data sources. Based on the existing literature, an improved model would include measures of such important additional contextual variables as the quality of the child's peer-group relations, the quality of the child's non-parent adult support network, parental mental health and stress, residential stability, school quality, and additional neighborhood quality indicators, including poverty concentration, the crime rate, and recreational and after-school resources. Outcome measures for child health, social/emotional well-being, and learning skills that supplement the parent and child reports used in this study are desirable, too. The full array of indicators that might appear in an ideal model are not yet available in any single dataset, although recent advances in developing datasets of linked administrative records are a promising development, especially for sub-national analysis (Culhane et al. 2010). The PSID/CDS itself, with its large number of variables assessing parental behavior and the parent-child relationship, can be used to construct alternative or additional measures of these important contextual indicators. Researchers can also use the PSID longitudinally to investigate how the experience of specific deprivations at earlier stages in the child's life might influence adolescent outcomes, an intriguing line of research given the increasing evidence of the importance of age at which deprivation is experienced to outcomes over the lifecourse (KIDS COUNT 2013).

\section{Conclusions and Policy Recommendations}

This paper presents descriptive findings from an experimental, multidimensional measure of deprivation for older children and adolescents in the United States. The measure comprises 17 indicators encompassing a range of economic, environmental, child, and parental characteristics shown in the research literature to be associated with child development outcomes. Confirming other research, we find that our multidimensional measure provides valuable information about children at risk for poor development outcomes that is not captured by more standard income poverty and material hardship measures. Although children in low-income families are more likely than children in higher-income families to experience each of the 16 additional (non-income) deprivations included in the study, income is an inadequate proxy for some important developmental risk factors. Specifically, bivariate correlation analysis shows income is strongly associated with variables measuring housing and neighborhood conditions and with parental employment status, health, and education. It is moderately correlated with variables measuring child health insurance coverage, inclusive family activities, child health, child social/emotional well-being, and child experience of being threatened with a weapon. Finally, income is weakly correlated with parental warmth, child basic learning skills, child exposure to bullying, and child cultural isolation. Our finding of weak income correlations with parental warmth and basic learning skills are surprising, given the substantial theoretical and empirical literature supporting such associations. Multivariate regression analysis provides supporting evidence that deprivation indicators in addition to low income are important for identifying children at risk for experiencing poor health, poor basic learning skills, and low social/emotional wellbeing. 
We find that $26 \%$ of American children live in low-income families (defined as having less than half of national net disposable median income), while $45 \%$ are disadvantaged, defined as experiencing three or more deprivations. Children from low-income families are more likely to experience additional deprivations compared to children from higher-income families and are much more likely to be severely disadvantaged, defined as experiencing more than five deprivations. More than onethird of these children report low social/emotional well-being compared to one- quarter of all children. With respect to demographic characteristics, boys are more likely to be disadvantaged than girls and black and Hispanic children are much more likely to be disadvantaged than white children, findings consistent with an earlier multidimensional well-being index for U.S. children using broadly similar domains but a different data source and different specific indicators (Moore, et al. 2008). Hispanic and black children are more likely to experience every specific deprivation except being bullied (Hispanics) and being bullied, having poor basic learning skills and having poorlyeducated parents (blacks). The white-Hispanic and white-black disparities in deprivation incidence are especially large with respect to the economic indicators. Black and Hispanic children are also much more likely than white children to experience a large number of deprivations.

By measuring the incidence of specific deprivations among children and examining associations between deprivations, the multidimensional approach contributes important insights for social policy. For example, about one-quarter of American older children and adolescents report low social/emotional well-being, poor basic learning skills, and being bullied. However, these deprivations are not strongly correlated as might be expected, suggesting a need for interventions addressing each of the three deprivations independently.

Conversely, the strong associations between income and family financial stress, housing and neighborhood conditions, and parental employment, health, and educational attainment suggest the utility of coordinated policy interventions at the macroeconomic, neighborhood, and two-generational family levels. Policies to raise family incomes through job creation and work supports are critical to improving child wellbeing. Indeed, a compelling body of new research has linked relatively small annual income supplements given to poor families (on the order of $\$ 1,000$ to $\$ 4,000$ ) to significant gains in school-age children's achievement and academic outcomes (Akee et al. 2010; Dahl and Lochner 2012; Duncan, Morris and Rodrigues 2011). But evidence from this and other multidimensional studies of deprivation and well-being suggests that programs that simply address income may be less effective in improving healthy child development as those that take a holistic and ecological approach, addressing specific deprivations in their family, social, and environmental contexts. As three prominent child poverty researchers recently wrote:

Programs that offer greatest promise may be those that consider ways to remedy both the material and the psychosocial conditions faced by families in poverty. Building integrated platforms of service delivery that target poverty reduction and health and human capital promotion is not a small task. That said, such integrated models of family behavioral change and material support may yield benefits in unanticipated ways (Aber, Morris and Raver 2012). 


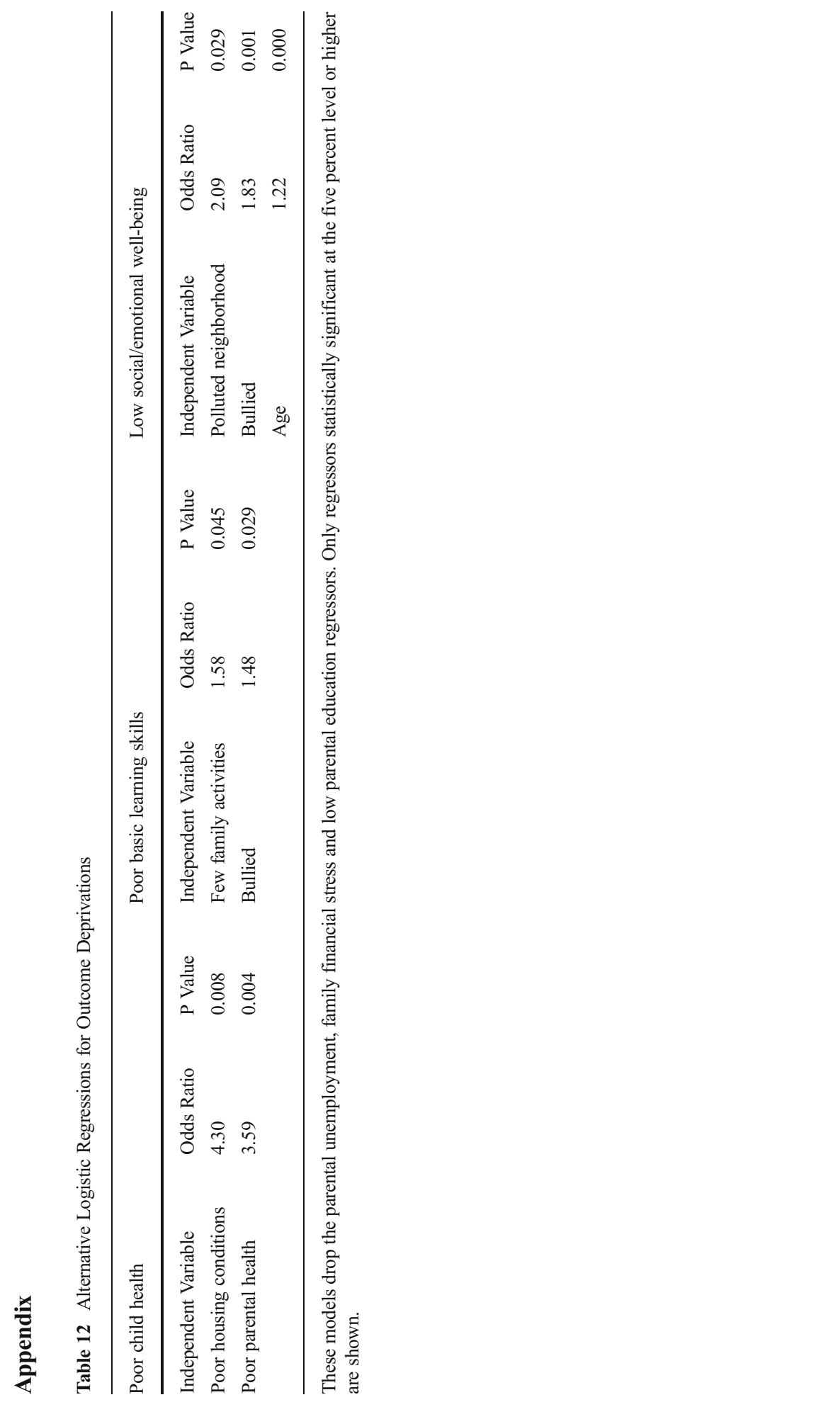


Such integrated and place-based models, pioneered by the Harlem Children's Zone and other community-based organizations, have captured the attention of federal policymakers. President Obama's Neighborhood Revitalization Initiative, launched in 2010, coordinates federal investments in education, health, public safety, housing, economic development, and human services in high-poverty neighborhoods. The federal Centers for Disease Control and Prevention uses a social-ecological model to guide some public health initiatives, identifying risk factors and developing prevention strategies at the individual, close relationship, community, and broader societal levels. An understanding of family and child well-being across multiple, interactive dimensions can help inform and evaluate these and other promising innovations in social policy.

Acknowledgments We wish to thank Mark Levitan, Kristin Moore and Jane Waldfogel for commenting insightfully on an earlier draft and two anonymous journal reviewers for very helpful comments. All remaining errors are the authors' own.

\section{References}

Aber, J. L., Gershoff, E. T., \& Brooks-Gunn, J. (2002). Social exclusion in the United States: Identifying potential indicators. In A. J. Kahn \& S. B. Kamerman (Eds.), Beyond child poverty: The social exclusion of children (pp. 245-286). New York: Institute for Child and Family Policy at Columbia University.

Aber, L., Morris, P., \& Raver, C. (2012). Children, families and poverty: Definitions, trends, emerging science and implications for policy. Social Policy Report, 26(3), 1-19.

Akee, R. K. Q., et al. (2010). Parents' incomes and children's outcomes: A quasi-experiment using transfer payments from casino profits. American Economic Journal: Applied Economics, 2(1), 86-115.

Alkire, S., \& Foster, J. (2011). Counting and multidimensional poverty measurement. Journal of Public Economics, 95, 476-487.

Atkinson, A. B., Marlier, E., \& Nolan, B. (2004). Indicators and targets for social inclusion in the European Union. Journal of Common Market Studies, 42(1), 47-75.

Axinn, W., Duncan, G. J., \& Thornton, A. (1997). The effects of parents' income, wealth, and attitudes on children's completed schooling and self-esteem. In G. J. Duncan \& J. Brooks-Gunn (Eds.), Consequences of growing up poor (pp. 518-540). New York: Russell Sage.

Ben-Arieh, A. (2005). Where are the children? Children's role in measuring and monitoring their well-being. Social Indicators Research, 74, 573-596.

Ben-Arieh, A. (2008). The child indicators movement: Past, present, and future. Child Indicators Research, 1, 3-16. Bradshaw, J., \& Finch, N. (2003). Overlaps in dimensions of poverty. Journal of Social Policy, 32, 513-525.

Bronfenbrenner, U. (1979). The ecology of human development: Experiments by nature and design. Cambridge, MA: Harvard University Press.

Brooks-Gunn, J., \& Duncan, G. J. (1997). The effects of poverty on children.The Future of Children, 7, 55-71.

Brooks-Gunn, J., Duncan, G. J., \& Aber, J. L. (Eds.). (1997a). Neighborhood poverty: Context and consequences for children. New York: Russell Sage.

Brooks-Gunn, J., et al. (1997b). Lessons learned and future directions for research on the neighborhoods in which children live. In J. Brooks-Gunn, G. J. Duncan, \& J. L. Aber (Eds.), Neighborhood poverty: Context and consequences for children (pp. 279-297). New York: Russell Sage.

Chen, E., Schreier, H. M. C., \& Chan, M. (2012). Dissecting pathways for socioeconomic gradients in childhood asthma. In B. Wolfe, W. Evans, \& T. E. Seeman (Eds.), The biological consequences of socioeconomic inequalities (pp. 103-125). New York: Russell Sage.

Cohen, S., et al. (2010). Childhood socio economic status and adult health. Annals of the New York Academy of Sciences, 1186, 35-55.

Consejo Nacional de Evaluación de la Política de Desarrollo Social. (2009). Comunicado de Prensa No. 008/ 09. Retrieved July 2013 from http://www.coneval.gob.mx/SalaPrensa/Paginas/Comunicados_de_prensa/ Comunicado_2009017.aspx

Consejo Nacional de Evaluación de la Política de Desarrollo Social. (2012). Comunicado de Prensa No. 003. Retrieved July 2013 from http://www.coneval.gob.mx/Informes/Coordinacion/Pobreza_2012/ COMUNICADO_PRENSA_003_MEDICION_2012.pdf 
European Commission. (2013). Poverty and Social Exclusion web page. Retrieved July 2013 from http://ec. europa.eu/social/main.jsp?catId=751\&langId=en

Crouter, A. C., Head, M. R., \& McHale, S. M. (2004). Family time and the psychosocial adjustment of adolescent siblings and their parents. Journal of Marriage and the Family, 66, 147-162.

Culhane, D. P., et al. (2010). Connecting the dots: The promise of integrated data systems for policy analysis and systems reform. Philadelphia, PA: Actionable Intelligence for Social Policy, University of Pennsylvania. Retrieved March 2014 from http:/www.aisp.upenn.edu/wp-content/uploads/2013/05/Connecting-the-Dots-AISP.pdf

Cummins, R. A. (2000). Personal income and subjective well-being: A review. Journal of Happiness Studies, $1,133-158$.

Dahl, G. B., \& Lochner, L. (2012). The impact of family income on child achievement: Evidence from the Earned Income Tax Credit. American Economic Review, 102(5), 1927-1956.

Desha, L. N., Nicholson, J. M., \& Ziviani, J. M. (2011). Adolescent depression and time spent with parents and siblings. Social Indicators Research, 101, 233-238.

Duncan, G. J., \& Raudenbush, S. W. (2001). Neighborhoods and adolescent development: How can we determine the links? In A. Booth \& N. Crouter (Eds.), Does it take a village? Community effects on children, adolescents and families (pp. 105-136). Mahway, NJ: Lawrence Erlbaum Associates, Inc.

Duncan, G. J., Morris, P. A., \& Rodrigues, C. (2011). Does money really matter? Estimating impacts of family income on young children's achievement with data from random-assignment experiments. Developmental Psychology, 47(5), 1263-1279.

Engelhardt, W. \& Skinner, C. (2013). Knowing what works: States and cities build smarter social policy with new and improved poverty measurement. New York: National Center for Children in Poverty. Retrieved July 2013 from http://www.nccp.org/publications/pdf/text_1081.pdf

Evans, W., Wolfe, B., \& Adler, N. (2012). The SES and health gradient: A brief review of the literature. In B. Wolfe, W. Evans, \& T. E. Seeman (Eds.), The biological consequences of socioeconomic inequalities (pp. 1-37). New York: Russell Sage.

Farah, M. J., et al. (2007). The developing adolescent brain in socioeconomic context. In D. Romer \& E. Walker (Eds.), Adolescent psychopathology and the developing brain: Integrating brain and prevention science (pp. 373-387). New York: Oxford University Press.

Federal Interagency Forum on Child and Family Statistics. (2013). America's children: Key national indicators of well-being, 2013. Washington, DC: U.S. Government Printing Office. Retrieved July 2013 from http:// childstats.gov/pdf/ac2013/ac 13.pdf

Fernandes, L., Mendes, A., \& Texeira, A. (2012a). A review essay on the measurement of child well-being. Social Indicators Research, 106, 239-257.

Fernandes, L. Mendes, A., \& Texeira, A. (2012b). A weighted multidimensional index of child well-being which incorporates children's individual perceptions. Social Indicators Research. Published online 18 Oct. 2012

Gerard, J. M., \& Buehler, C. (2004). Cumulative environmental risk and youth problem behavior. Journal of Marriage and the Family, 66, 702-720.

Gershoff, E. T., et al. (2007). Income is not enough: Incorporating material hardship into models of income associations with parenting and child development. Child Development, 78(1), 70-95.

Gordon, D., et al. (2000). Poverty and social exclusion in Britain. York, UK: Joseph Rowntree Foundation. Retrieved July 2013 from http://www.bristol.ac.uk/poverty/pse/

Gruenewald, T. L. (2012). Biological imprints of social status: Socioeconomic gradients in biological markers of disease risk. In B. Wolfe, W. Evans, \& T. E. Seeman (Eds.), The biological consequences of socioeconomic inequalities (pp. 63-102). New York: Russell Sage.

Guryan, J., Hurst, E., \& Kearney, M. (2008). Parental education and parental time with children. Journal of Economic Perspectives, 22, 23-46.

Haveman, R., \& Wolfe, B. (1995). The determinants of children's attainments: A review of methods and findings. Journal of Economic Literature, 33(4), 1829-1879.

Jantii, M. (2009). Mobility in the United States in comparative perspective. In M. Cancian \& S. Danzinger (Eds.), Changing poverty, changing policies (pp. 180-200). New York: Russell Sage.

Jiang, Y., Ekono, M. \& Skinner C. (2014). Basic facts about low-income children: Children under 18 years, 2011. New York: National Center for Children in Poverty. Retrieved Feb. 2014 from http://www.nccp.org/ publications/pdf/text 1089.pdf

Kahn, A. J., \& Kamerman, S. B. (2002). Beyond child poverty: The social exclusion of children. New York: Institute for Child and Family Policy at Columbia University.

KIDS COUNT (2013). The first eight years: Giving kids a foundation for lifetime success. Baltimore, MD: Annie E. Casey Foundation

Land, K. C., Lamb, V. L., \& Mustillo, S. K. (2001). Child and youth well-being in the United states, 19751998: Some findings from a new index. Social Indicators Research, 56, 241-320. 
Leventhal, T., \& Brooks-Gunn, J. (2000). The neighborhoods they live in: The effects of neighborhood residence on child and adolescent outcomes. Psychological Bulletin, 126(2), 309-337.

Leventhal, T., \& Newman, S. (2010). Housing and child development. Children and Youth Services Review, $32,1165-1174$.

Magnuson, K., \& Votruba-Drzal, E. (2009). Enduring influences of childhood poverty. In M. Cancian \& S. Danzinger (Eds.), Changing poverty, changing policies (pp. 153-179). New York: Russell Sage.

Malik, K. (2013). Human Development Report 2013. Technical Note 4. Multidimensional Poverty Index. Retrieved July 2013 from http://hdr.undp.org/en/media/HDR\%202013\%20technical\%20notes\%20EN. pdf

McLoyd, V. C., et al. (1994). Unemployment and work interruption among African American single mothers: Effects on parenting and adolescent socioemotional functioning. Child Development, 65, 562-589.

Menaghan, E. G., Kowaleski-Jones, L., \& Mott, F. L. (1997). The intergenerational costs of parental social stressors: Academic and social difficulties in early adolescence for children of young mothers. Journal of Health and Social Behavior, 38, 72-86.

Messer, L. C., et al. (2006). The development of a standardized neighborhood deprivation index. Journal of Urban Health: Bulletin of the New York Academy of Medicine, 83(6), 1041-1062.

Moore, K. A., et al. (2008). A microdata child well-being index: Conceptualization, creation, and findings. Child Indicators Research, 1, 17-50.

Moore, P. M., Huebner, E. S., \& Hills, K. J. (2012). Electronic bullying and victimization and life satisfaction in middle school students. Social Indicators Research, 107, 429-447.

Consejo Nacional de Evaluación de la Política de Desarrollo Social. (2009). Comunicado de Prensa No. 008/ 09. Retrieved July 2013 from http://www.coneval.gob.mx/SalaPrensa/Paginas/Comunicados_de prensa/ Comunicado_2009017.aspx

Consejo Nacional de Evaluación de la Política de Desarrollo Social. (2012). Comunicado de Prensa No. 003. Retrieved July 2013 from http://www.coneval.gob.mx/Informes/Coordinacion/Pobreza_2012/ COMUNICADO_PRENSA_003_MEDICION_2012.pdf

Nansel, T. R., et al. (2001). Bullying behaviors among U.S. youth: Prevalence and association with psychological adjustment. JAMA, 285, 2094-2110.

Nelson, J., Martin, K. \& Featherstone, G. (2013). What works in supporting children and young people to overcome persistent poverty? A review of UK and international literature. Belfast: Office of the First Minister and Deputy First Minister (OFMDFM)

Oxford Poverty and Human Development Initiative. (2013a). Colombia's Multidimensional Poverty Index web page. Retrieved July 2013 from http://www.ophi.org.uk/policy/national-policy/colombia-mpi/

Pedersen, S., \& Revenson, T. A. (2005). Parental illness, family functioning, and adolescent well-being: A family ecology framework to guide research. Journal of Family Psychology, 19, 404-419.

Peters, H. E., \& Mullis, N. C. (1997). The role of family income and sources of income in adolescent achievement. In G. J. Duncan \& J. Brooks-Gunn (Eds.), Consequences of growing up poor (pp. 340381). New York: Russell Sage.

Oxford Poverty and Human Development Initiative. (2013b). Policy: International, National and Subnational Applications web page. Retrieved July 2013 from http://www.ophi.org.uk/policy/national-policy/

Sastry, N. \& Duffy, D. (2012). An assessment of the national representativeness of children in the 2007 Panel Study of Income Dynamics. PSID Survey Research Center, Institute for Social Research, University of Michigan, Technical Services Paper No. 12-01

Sharkey, P. T., et al. (2012). The effect of local violence on children's attention and impulse control. American Journal of Public Health, 102(12), 2287-2293.

Singh, G. K., \& Kogan, M. D. (2007). Widening socioeconomic disparities in US childhood mortality, 19692000. American Journal of Public Health, 97(9), 1658-1665.

Spencer, M. B., et al. (1997). An alternative approach to assessing neighborhood effects on early adolescent achievement and problem behavior. In J. Brooks-Gunn, G. J. Duncan, \& J. L. Aber (Eds.), Neighborhood poverty: Context and consequences for children (Vol. 1, pp. 145-163). New York: Russell Sage.

Tubbs, C., \& Aber, L. (2013). Cascading effects of parental stress. The American Prospect, 24(3), 69-71. University of Michigan, Institute for Social Research. (2012). The Panel Study of Income Dynamics Child Development Supplement: User Guide for CDS-III. Retrieved January 2013 from http://psidonline. isr.umich.edu/CDS/cdsiii_userGd.pdf

Valois, R. F., et al. (2001). Relationship between life satisfaction and violent behaviors among adolescents. American Journal of Health Behavior, 25, 353-366.

Waldfogel, J. (2006). What children need. Cambridge, MA: Harvard University Press.

Whelan, C., et al. (2001). Income deprivation and economic strain: An analysis of the European Community Household Panel. European Sociological Review, 17(4), 357-372. 